\title{
The role of legal and moral norms to regulate the behavior of texting while driving
}

Hyang-Sook Kim

Department of Mass Communication and Communication Studies, Towson
University, 8000 York Road, Towson, MD 21252, United States

Abstract

Despite a nationwide lawful effort to regulate texting-while-driving behavior, little change has been reported. This study assessed the effect of current legal enforcement on attitudinal and behavioral responses toward texting while driving in conjunction with potential influences of two types of perceived norms - legal and moral. An online survey was conducted with 313 college students recruited from three states where the history of a banning law of texting while driving varied (more than 3 years, less than 1 year, and none). The students self-reported perceived legal norm, perceived moral norm, perceived risk of texting while driving, frequency of texting while driving, attitude toward texting while driving, and intention of texting while driving. General linear model analyses revealed that the mere presence of legal enforcement showed a negative relationship with frequency of behavior only for the state with the banning law in effect more than 3 years. While the perceived legal norm showed inconsistent relationships with outcome variables, the perceived moral norm appeared most promising to discourage texting while driving among young drivers. A banning law for texting-while-driving behavior not only backfired on the actual behavior in a short-term effect, but also required a long-term exposure of the law to change the actual behavior among college students. On the other hand, cultivation of a moral norm to regulate the behavior of texting while driving is particularly encouraged in that the stable nature of this psychological variable can play a role to suppress possible reactance evoked by an external force. Policy makers are encouraged to harness their approach to regulate young drivers' texting while driving with the strategy that appeals to the drivers' moral beliefs rather than simply forcing them to comply with the law.

\section{Introduction}

In 2014, a total of 3179 people died in crashes caused by distracted driving, 285 of whom were teen drivers (NHTSA, 2016). In particular, texting while driving was identified as one of the highestranked distracted driving behaviors (Federal Motor Carrier Safety Administration, 2009). To regulate this fatal behavior, 46 states in the United States currently ban texting while driving 
(Governors Highway Safety Association, 2016). Yet, the success of legal enforcement has not been clearly documented (Jacobson \& Gostin, 2010; Ling, Bertel, \& Sundsøy, 2012). Other countries around the world such as Germany and Austria (Vollrath, Huemer, Teller, Likhacheva, \& Fricke, 2016), Norway (Backer-Grondahl \& Sagberg, 2011), Spain (Prat, Gra, Planes, González-Iglesias, \& Sullman, 2015), Australia (Beanland, Fitzharris, Young, \& Lenné, 2013; White, Hyde, Walsh, \& Watson, 2010), New Zealand (Hallett, Lamber, \& Regan, 2011, 2012), Canada (Nurullah, Thomas, \& Vakilian, 2013; Tucker, Pek, Morrish, \& Ruf, 2015), and China (Shi, Xiao, \& Atchley, 2016; Zhou, Yu, \& Wang, 2016) have also paid serious attention to the undesirable consequences of distracted driving, especially the use of cell phones for various communication activities, including texting.

Beside the diagnosis of perceived risks of texting while driving and other distracted driving activities (e.g., Vollrath et al., 2016; Weller, Shackleford, Dieckmann, \& Slovic, 2012; White et al., 2010), a common yet vital research focus in previous studies has been the effectiveness of normative approaches to regulating young adults' risky behaviors, including texting while driving (e.g., Atchley, Hadlock, \& Lane, 2012; Benson, McLaughlin \& Giles, 2015; Lipperman-Kreda, Paschall, \& Grube, 2009; Marcil, Bergeron, \& Audet, 2001; Nemme \& White, 2010; Prat et al., 2015; Riquelme, Al-Sammak, \& Rios, 2010; Tian \& Robinson, 2016; Waddell \& Wiener, 2014). General findings from this line of research indicate that norms that people perceived as an external force (e.g., a banning law, social norms spread out through public campaigns or media publicity) did not gain much success in repressing their intention to text while driving. For example, a longitudinal study of two trend surveys over two years in a state since a banning law of cell phone use while driving was implemented observed little change of actual behavior among drivers, including texting (Foss, Goodwin, McCartt, \& Hellinga, 2009; Goodwin, O’Brien, \& Foss, 2012). Moreover, drivers' high level of perception on possible social sanction as a result of texting while driving did not necessarily operate as a critical source of intervening in the drivers' actual behavior of texting while driving (Atchley et al., 2012; O’Brien, Goodwin, \& Foss, 2010).

One of the possible explanations of constant engagement with texting while driving among young adults in spite of a high level of perceived risks of the behavior is that this particular behavior is rather habitual or automatic than mindful, which seems hardly shakable by external stimuli such as legal enforcement and intervention campaigns. For instance, Skierkowsk and Wood (2012) found high dependency on texting as the primary communication form among young adults, which could account for an automatic action to reply to texts even in a driving situation in order not to experience anxiety resulting from not being responsive to texts. Bayer and Campbell (2012) further noted that the general habit of daily use of a cell phone could be differentiated from automatic texting behavior - reading texts, in particular-while driving. Another obstacle to successful intervention of the behavior of texting while driving is the susceptibility of young adults to a peer culture of approval of the behavior. This age group has been known to faithfully comply with peer norms related to risky behaviors (e.g., Beck \& Watters, 2016; Manning, 2009; Riquelme et al., 2010).

Likewise, it seems that external wheels that simply try to drag young drivers to obey, such as implementation of a banning law or public communication of social disapproval of the behavior, 
would not be promising due to their susceptibility to existing habits associated with cell phone use (e.g., Bayer \& Campbell, 2012; Weller et al., 2012) in addition to peer influence (e.g., Atchley et al., 2012; Waddell \& Wiener, 2014). However, it is inconclusive yet whether legal enforcement would be hopeless whatsoever solely based on findings from previous studies for three reasons. First, previous studies assessed the effectiveness of legal enforcement by comparing the actual behavior of cell phone use while driving between right before the law was enforced and after a certain period of time of the law implementation in one state, which might not be identical to the observations found for texting while driving in other states (e.g., Goodwin et al., 2012). And second, previous studies did not examine the perceived legal norm as a result of implementation of the banning law to confirm its effectiveness or lack thereof. Lastly, one's internal, psychological regulation system represented by perceived moral norm has not been fully examined in the context of interplaying with an external regulation system operating by lawful restrictions (c.f., Benson et al., 2015; Gauld, Lewis, \& White, 2014; Nemme \& White, 2010). Thus, the present study aimed to disambiguate the relationships among the presence (versus absence) of lawful restriction to texting while driving in various degrees and two psychosocial variables - perceived legal and moral norms - to predict not only attitude and behavioral intention of texting while driving but also perceived risks and frequency of the behavior.

\subsection{The role of legal and moral norms in the context of texting while driving}

Numerous studies have explicated norms to understand young adults' engagement with risky behaviors in spite of their consciousness to severe, undesirable consequences of such behaviors (e.g., Lewis \& Thombs, 2005; Marcil et al., 2001; Myklestad \& Rise, 2008; Neighbors, Lee, Lewis, Fossos, \& Larimer, 2007; Tian \& Robinson, 2016). These studies that tested the family of reasoned action model, including the theory of planned behavior (Fishbein \& Ajzen, 2010), focused on two types of norms - the injunctive norm (i.e., a standardized value of social (dis)approval of a behavior given a standard in society) and the descriptive norm (i.e., a dominant culture that mostly practices a behavior in various contexts connected to risky behaviors) (Manning, 2009, 2011; Rimal \& Lapinski, 2015) - to examine the predictability of the effect of these norms on one's intention to perform a risky behavior via favorable attitude toward the behavior (e.g., Benson et al., 2015; Prat et al., 2015; Tian \& Robinson, 2016). These previous studies generally found that the actual behavior would continue unless the unspoken acceptance of texting while driving among young drivers was entirely revamped, which seems unlikely.

\subsubsection{Potential problems with equating legal enforcement with perceived legal norm}

Another type of norm, legal norm, has been also addressed in the research about normative influences on perceived risks and behavior in a brief manner (Rimal \& Lapinski, 2015). The main difference of legal norm from social norms emerges from a high (versus low or none for social norms) degree of threats to be sanctioned (Baier, 2013, p. 61). Other risky behaviors studied largely in the context of communication and social influence do not necessarily seem to have a direct connection to the highest level of sanction as a result of engaging in behaviors such as binge drinking (e.g., Lewis \& Thombs, 2005), unprotected sexual activity (e.g., Turchik \& Gidycz, 
2012), and drug abuse (e.g., Booth, Stewart, Curran, Cheney, \& Borders, 2014). However, some risky behaviors, including texting (or cell phone use in general) while driving, are likely to result in legally confined situations in addition to severe casualties of both individuals who engage in the behavior and others (e.g., Wilson \& Stimpson, 2010).

Aligned with this conceptual definition of legal norm, previous studies found that legal or institutionally legitimate norms had a short-term effect, especially in young people's alcohol consumption behavior (e.g., Lipperman-Kreda et al., 2009; Paschall, Grube, Thomas, Cannon, \& Treffers, 2012). For instance, Lipperman-Kreda et al. (2009) found that the amount of students' alcohol consumption decreased for the first 30 days when the students perceived the enforcement of regulating alcohol consumption on campus. Paschall et al. (2012) also found that youths' underage drinking was controlled by legal enforcement in a community where the perceived norm about drinking in the community was consistent with the legal norm enforced.

However, in the context of texting while driving, the presence of legal enforcement might not effectively alert young drivers about immediate sanction as a result of their risky behavior on the road. When people were asked to sentence a driver who caused a car accident and hit a passenger due to texting while driving, they did not necessarily impose a high level of lawful decision for the driver although they harshly criticized the driver (Atchley et al., 2012). Furthermore, the level of perceiving the presence of legal enforcement about banning cell phone use for the first 5 months since the law was enforced was not higher than it was before the law was in place among teenage drivers (Goodwin et al., 2012).

\subsubsection{Moral norm as internal regulation system}

Previous literature often suggests the importance of internally driven motivations to perform a behavior (e.g., Deci, Eghrari, Patrick, \& Leone, 1994). In this vein, another normative approach that could alter the mindset of young drivers about texting while driving is the moral norm. The moral norm is one's inner "sense of moral obligation" to determine rightfulness against wrongness based on the values standardized in the society where the person belongs (Ajzen, 1991; Gauld et al., 2014, p. 287). Through a series of studies, Godin, Conner, and Sheeran (2005) investigated how one's perception on "moral correctness of a behavior" (p. 497) would change one's behavior (e.g., smoking, speeding, physical activity). They found that the positive effect of the moral norm was present for the behaviors involved in the situations only where severely negative outcomes were visible, such as smoking and violation of speed limit when driving, not for physical activity.

A few studies tested the potential influence of the moral norm on the likelihood of behavior intention for the case of texting while driving along with other possible predictors (Benson et al., 2015; Elliott, Thomson, Robertson, Stephenson, \& Wicks, 2013; Gauld et al., 2014). For instance, Elliott et al. (2013) included the moral norm in their testing of an extended theory of planned behavior model and found its negative effect on the texting-while-driving behavioral intention. However, this effect was not greater than the effects of the descriptive norm, which contributed to the increase of behavioral intention. Later, Benson et al. (2015) found significantly 
negative correlations between drivers' moral norms and attitudes toward and intention of texting while driving among 150 adult drivers with ages ranging from 18 to 69. Gauld et al. (2014) also found that the moral norm would decrease the likelihood of texting while driving via behavioral intention. However, it is not known whether the moral norm comes into play with the legal norm or operates independently to intervene in young drivers' texting-while-driving behavior.

\subsection{Inconsistency in exhibiting perceived risks and attitude and behavior among young adults}

Besides the speculation of the role of both the legal and moral norms in terms of their potential effects on young drivers' texting-while-driving behavior, previous literature also questioned the relationship between legal enforcement and perceived risks. Young drivers acknowledged a greater risk of texting while driving, which did not necessarily prevent them from engaging in the behavior (Jacobson \& Gostin, 2010). Atchley, Atwood, and Boulton (2011) administered a survey with 348 college students, who reported a relatively high level of perceived risks of texting while driving (i.e., greater than 5.0 for both initiating and replying to texts and 4.63 for reading texts while driving on a 7-point scale). However, the students' perception of the risk did not echo the behavior of replying to and reading texts, while initiating texts occurred less often when the students' perception of the risk was greater. Weller et al. (2012) also found that young drivers aged 17-28 years strongly exhibited a reliance on cell phones, which indeed was attributed to texting while driving; however, their perceived risk of texting while driving did not make much difference in terms of their actual behavior. Although a study surveying 414 Chinese adult drivers found a negative correlation between perceived risk and texting while driving, they still exhibited a dominant behavior of talking on the cell phone while driving regardless of the high level of perceived risk of that behavior (Shi et al., 2016).

This little transfer effect of perceived risks to the actual behavior of texting while driving could be attributed to the lack of internalization of focusing on undesirable consequences from the behavior. Pawson, Wong, and Owen (2011) noted that the success of legal enforcement fell under doubt because people did not personally internalize the importance of the outcomes of the behaviors (e.g., smoking in a car when children were present). This assumption has not been directly tested in the context of texting while driving, however. Furthermore, it is inconclusive to confirm presence or absence of the positive effect of perceived moral norm on one's perception of the risk of texting while driving which could be transferred to actual behavior.

\subsection{Study hypotheses}

Thus far, previous literature points to two ways of reasoning psychosocial responses toward two types of norms, legal and moral, in conjunction with the presence of legal enforcement. First, it seems still debatable to conclude the effects of legal enforcement in either a positive or negative direction for texting-while-driving banning laws unless drivers' perceived legal norm is properly measured at a different point of time. Although several studies found some short-term or slight long-term effects of the banning law for cell phone use while driving (e.g., Goodwin et al., 2012; Riquelme et al., 2010), findings of these studies cannot warrant the same results for the effect of perceived legal norm on attitude and behavior of texting while driving among young adults. In 
other words, it needs further investigation to confirm whether legal enforcement sufficiently and properly alerts young drivers about the probability of legal sanction at a perceptual level. Thus, it is suggested to measure the perceived legal norm among young drivers and compare it across different states where the history of legal enforcement of regulating texting while driving varies.

Second, the influence of the perceived moral norm has not been compared to that of the perceived legal norm in terms of the different functions of these two norms - one's internal versus external psychosocial systems - on regulating one's attitude toward and intention of texting while driving along with perceived risk of the behavior. The external force with a high level of sanction may not immediately confine one's behavior (e.g., Goodwin et al., 2012). Furthermore, it is still uncovered whether the combination of legal sanction and moral obligation would come into play for young drivers to keep the value of no texting while driving. Thus, the following two hypotheses and two research questions are proposed for the present study.

H1: The perceived legal norm will be negatively associated with (a) attitude toward and (b) behavioral intention of texting while driving as well as (c) frequency of texting while driving, but positively associated with (d) perceived risks.

H2: The perceived moral norm will be negatively associated with (a) attitude toward and (b) behavioral intention of texting while driving as well as (c) frequency of texting while driving, but positively associated with $(d)$ perceived risks.

R1: Will the history of law enforcement to ban texting while driving moderate the relationships stated in $H 1$ and $H 2$ ?

R2: Will the perceived legal and moral norms interact each other to make a difference in (a) attitude toward and $(b)$ behavioral intention of texting while driving as well as (c) perceived risks and (d) frequency of texting while driving?

\section{Method}

\subsection{Procedure and participants}

In order to confirm potential residual effects of legal enforcement on one's perceived legal norm, an online survey using the Qualtrics Labs, Inc. software gathered data from three different states, Wisconsin, Florida, and South Carolina. At the time of data collection, Wisconsin had banned texting while driving for more than three years while Florida started the banning law of texting while driving approximately six months ago. South Carolina, on the other hand, had not implemented a banning law to legally regulate the behavior of texting while driving by the time of data collection. Thus, the current study recruited college students from three institutions-in Wisconsin, Florida, and South Carolina, respectively - to participate in an online survey in exchange for extra credit. From the original sample of 336 college students, students who were not current drivers $(n=23)$ were excluded from the main analyses. Therefore, a total of 313 usable cases were retained, comprising 125 students from Wisconsin, 104 students from Florida, and 84 students from South Carolina. 
Female students consisted of $67 \%$ of samples, and the average age of participants was 21.21 ( $S D=$ 3.48). White/Caucasian American was the dominant racial group (53\%), followed by Hispanic (23.6\%) and Black/African American (18.2\%).

\subsection{Measured variables}

\subsubsection{Perceived legal norm}

Participants rated four statements that estimated the likelihood of occurrence of legal enforcement against texting while driving using a 7-point scale, 1 being Not at all and 7 being Very much likely (i.e., If someone texted while driving in your state, he or she would be caught by the police; If someone texted while driving in your State, the police would catch and fine him or her; If someone used a cell phone while driving in your State, the police would catch and fine him or her; If someone made a call/answered the phone while driving in your State, the police would catch and fine him or her, $\alpha=0.93, M=3.26, S D=1.68$ ) (Lipperman-Kreda et al., 2009).

\subsubsection{Perceived moral norm}

An index of three items asked participants to indicate their personal beliefs regarding texting while driving (i.e., I would feel guilty if I texted while driving; I personally think that texting while driving is wrong; Texting while driving goes against my principles, $\alpha=0.82, M=4.68, S D=1.73$ ) (Nemme \& White, 2010).

\subsubsection{Perceived risk of texting while driving}

Participants rated the level of risks of behaviors related to texting while driving on three items (i.e., initiating/reading/ replying to a text $)$ using a 7-point scale $(1=$ Not at all dangerous, $7=$ Extremely dangerous, $\alpha=0.95, M=6.20, S D=1.17$ ) (Atchley et al., 2011).

\subsubsection{Frequency of texting while driving}

Four items asked participants to indicate frequency of reading, sending, and replying to texts as well as texting while driving one week prior to the participation in the survey on a 7-point scale, 1 being Never and 7 being Always ( $\alpha=0.95, M=3.43, S D=1.70)$ (Bayer \& Campbell, 2012).

\subsubsection{Attitude and behavioral intention}

Participants also reported their attitudes toward texting while driving on a 4-item index of a 7-point Likert scale (e.g., For me, texting while driving over the next month would be good, wise, valuable, and beneficial, $1=$ Not at all, $7=$ Very much likely, $\alpha=0.96, M=1.83, S D=1.36$ ) (Elliott et al., 2013). In addition, they answered three items of intention to text while driving (i.e., I intend/want/plan to text while driving over the next month) using 7-point Likert scale $(1=$ strongly disagree, $7=$ strongly agree, $\alpha=0.92, M=2.24, S D=1.50)$ (Elliott et al., 2013). 


\section{Results}

Main analyses were conducted using a general linear model analysis with the state, perceived legal norm, and perceived moral norm as three predictors of dependent variables, including attitude toward texting while driving and intention to text while driving, in addition to perceived risk of texting while driving and frequency of texting while driving. ${ }^{1}$ The analysis yielded a series of main effects and two-way interaction effects among three predictors-state, perceived legal norm, and perceived moral norm. Table 1 summarizes means and standard errors of measured variables per state.

\subsection{Main effects}

A main effect of state was found on the frequency of texting while driving, $F(2,301)=21.64, p<$ $.001)$. Specifically, the frequency of texting while driving among the students in Wisconsin was significantly lower $(L S M=2.81, S E=0.13)$ than those in the other two states, Florida $(L S M=4.06$, $S E=0.14)$ and South Carolina $(L S M=3.65, S E=0.16)$. Perceived risk of, attitude toward, and intention of texting while driving were not different across the three states.

Main effects of perceived legal norm were also found on the frequency of texting while driving $[F(1,301)=7.97, p<.01, \beta=0.14]$, perceived risk of texting while driving $[F(1,301)=5.46, p<$ $.05, \beta=0.09]$, and attitude toward texting while driving $[F(1,301)=4.51, p<.05, \beta=0.10]$. Contrary to expectations, the perceptions on legal enforcement as one's psychological presentation of the legal norm showed mixed relationships with perceived risk of texting while driving (supporting H1d with a very small standardized coefficient value of 0.09) and attitude toward texting while driving, as well as the frequency of actual behavior (not supporting H1a, H1b, and H1c).

Lastly, perceived moral norm yielded main effects on all dependent variables - frequency of texting while driving $[F(1,301)=34.24, p<.001, \beta=-0.30]$, perceived risk of texting while driving $[F(1$, $301)=34.24, p<.001, \beta=0.18]$, attitude toward texting while driving $[F(1,301)=20.57, p<.01$, $\beta=-0.17]$, and intention of texting while driving $[F(1,301)=16.22, p<.001, \beta=-0.20]$. Unlike the effect of the perceived legal norm, the perceived moral norm consistently played a role as an effective regulation system on not only actual behavior but also related psychological responses. Thus, $\mathrm{H} 2 \mathrm{~s}$ received support from the data.

\subsection{Interaction effects}

Regarding R1, an interaction effect between state and perceived legal norm was found on frequency of texting while driving, $F(2,301)=4.81, p<.01$. The frequency of texting while driving increased as the perceived legal norm also increased among participants in both Florida and Wisconsin, although the overall degree of frequency was higher among those in Florida than in Wisconsin. However, the perceived legal norm and the frequency of texting while driving showed the opposite direction of relationship among the participants in South Carolina (Fig. 1, left-hand side image).

\footnotetext{
${ }_{1}^{1}$ JMP 10.0 version was used for the analysis.
} 
An interaction effect between state and perceived moral norm was also found on frequency of texting while driving $[F(2,301)=2.98, p=.05]$. Perceived moral norm operated to thwart the frequency of texting while driving among all participants regardless of their residency state, while the degree of decrease in the frequency as the perceived moral norm increased appeared the greatest among those in Wisconsin, followed by South Carolina and Florida (Fig. 1, righthand side image). The state and perceived legal norm also yielded an interaction effect on intention to text while driving $[F(2,301)=4.72, p<.01]$. Similar to the patterns found in the interaction effect between state and perceived norm on the frequency of texting while driving, the perceived norm contributed the decrease of intention to text while driving most among the participants in Wisconsin, followed by South Carolina, while it did not make a difference in the intention of texting while driving among those in Florida (Fig. 2).

\section{Table 1}

Summary of least square means and standard errors for measured variables.

\begin{tabular}{llll}
\hline & \multicolumn{2}{l}{ State } & \\
\cline { 2 - 4 } & Wisconsin $(n=125)$ & Florida $(n=104)$ & South Carolina $(n=84)$ \\
\hline Perceived legal norm & $3.31(0.15)$ & $3.21(0.17)$ & $3.20(0.18)$ \\
Perceived moral norm & $5.01(0.15)^{\mathrm{a}}$ & $4.56(0.16)^{\mathrm{ab}}$ & $4.34(0.18)^{\mathrm{b}}$ \\
Attitude toward texting while driving & $1.64(0.12)$ & $2.01(0.13)$ & $1.90(0.15)$ \\
Intention to text while driving & $2.10(0.13)$ & $2.51(0.14)$ & $2.14(0.15)$ \\
Frequency of texting while driving & $2.81(0.13)^{\mathrm{a}}$ & $4.06(0.14)^{\mathrm{b}}$ & $3.65(0.16)^{\mathrm{b}}$ \\
Perceived risk of texting while driving & $6.08(0.10)$ & $6.36(0.11)$ & $6.18(0.13)$ \\
\hline
\end{tabular}

Note. Means sharing a letter in their subscript are not significantly different at $p<.05$. Standard errors are reported in parentheses, which use a pooled estimate of error variance. 

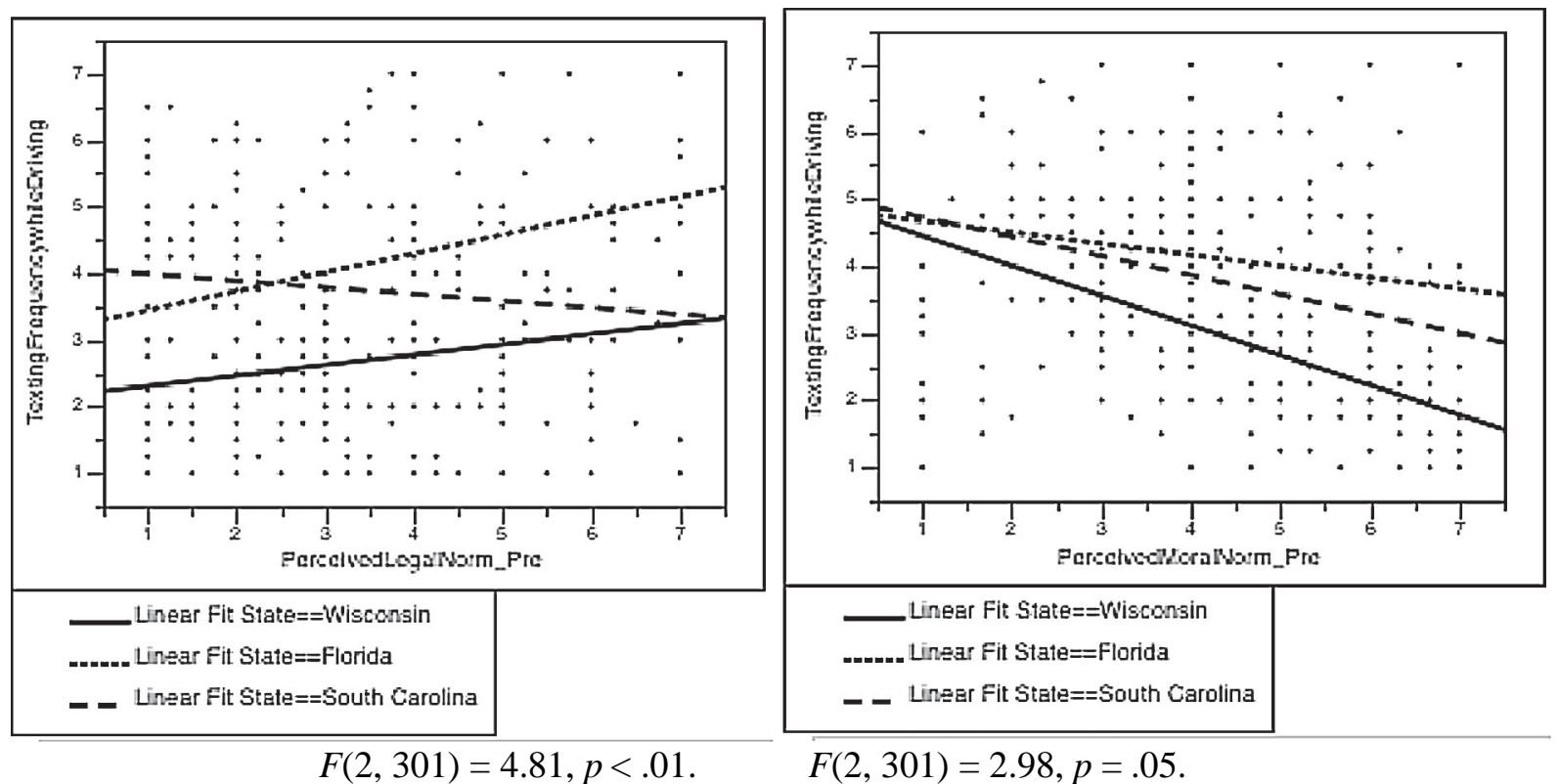

Fig. 1. Two-way interaction effects between state and perceived legal norm (left) and state and perceived moral norm (right) on frequency of texting while driving.

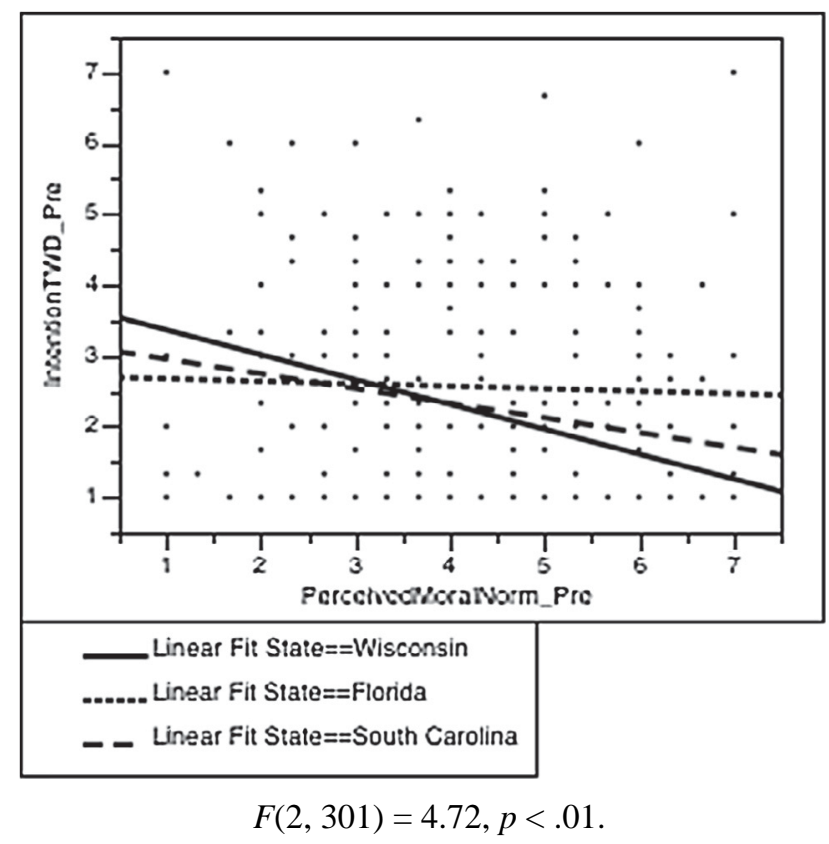

Fig. 2. Two-way interaction effect between state and perceived moral norm on intention to text while driving. 
Lastly, related to R2, the perceived legal and moral norms interacted in terms of showing different relationships with the intention of texting while driving, $F(1,301)=4.00, p<.05$. The perceived legal norm did not make much difference in participants' intention to text while driving when the participants showed a relatively low level of perceived moral norm. However, when the perceived moral norm was high, the intention of texting while driving increased as the perceived legal norm increased (Fig. $3^{2}$ ).

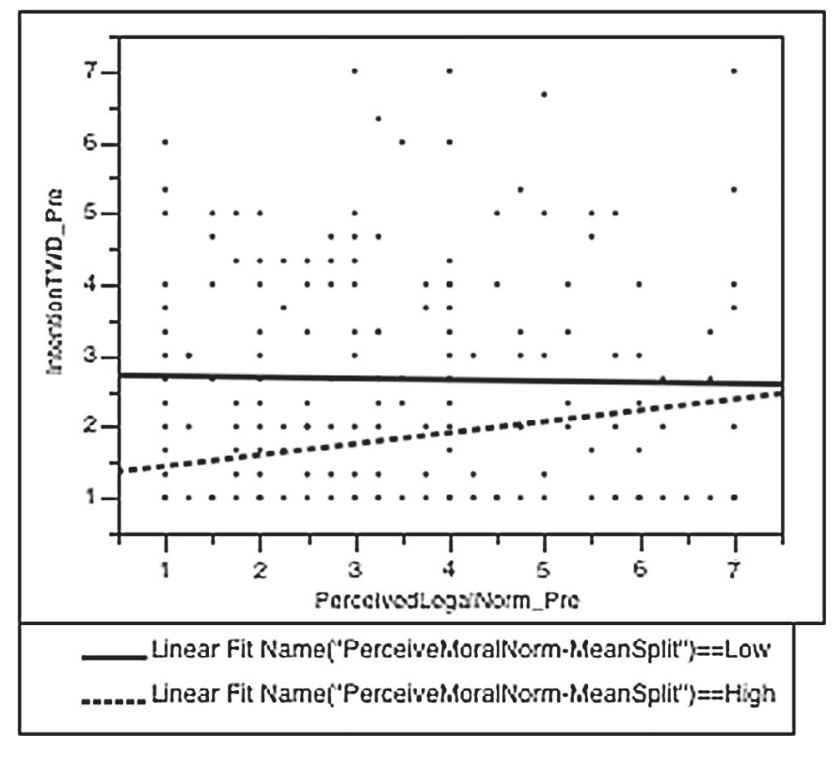

$$
F(1,301)=4.00, p<.05 .
$$

Fig. 3. Interaction effect between perceived legal norm and perceived moral norm on intention to text while driving.

\section{Discussion}

\subsection{Summary of findings}

First of all, perceived risks did not translate to young adults' behavior of texting while driving. Despite the different history of texting while banning law among the three states in the length of time the law had been in effect or if such a law was in place at all, participants in the three states did show a similar degree of perceived risk of texting while driving. The present study also found little effect of legal enforcement to evoke the proper corresponding psychological perception among the participants. Besides a small degree of positive relationship between the perceived legal norm and perceived risks $(\beta=0.09, p<.05)$, surprisingly, the perceived legal norm was positively, not negatively, associated with the frequency of texting-while-driving behavior $(\beta$ $=0.14, p<.01)$ and attitude toward the behavior $(\beta=0.10, p<.05)$. However, the positive

${ }^{2}$ A mean-split method of perceived moral norm was used solely for the purpose of visualizing this interaction effect. 
relationship between the perceived legal norm and the frequency of texting while driving was true among the participants in Wisconsin and Florida only, not of those in South Carolina (Fig. 1, left-hand side image).

On the other hand, one's stable sense of the mandate not to text while driving driven by one's internal moral system clearly showed negative relationships with attitude toward and intention of texting while driving in addition to likelihood of actual texting behavior while driving, while it showed a positive relationship with perceived risks of the behavior as expected. It must be noted, however, that this strong influence of an internal regulation system based on one's moral beliefs appeared differently among participants from the three states. The influence of the perceived moral norm was strongest for those living in Wisconsin, followed by South Carolina and Florida, to show the negative relationship with the frequency of texting while driving (Fig. 1, right-hand side image). A similar pattern was also found in the relationship between the perceived moral norm and intention to text while driving (Fig. 2). Lastly, an interaction effect between the perceived legal norm and perceived moral norm evidenced that the intention to text while driving was not swayed by the norm externally forced (i.e., perceived legal norm) when the students held relatively weak moral beliefs. However, the perceived legal norm somehow revamped one's intention to text while driving from the negative to positive direction even when the students held relatively high moral beliefs (Fig. 3).

\subsection{Problematic carry-over of legal enforcement to perceived legal norm}

Consistent with the findings from other studies about the limited effects of law enforcement for handheld cell phone use while driving (e.g., Goodwin et al., 2012; Riquelme et al., 2010), the present study found that the history of legal enforcement did not show any difference in essential psychological outcomes for texting while driving among college students. However, the frequency of the behavior was different such that the banning law for texting seemed to resonate with drivers only in the state where the banning law had been in effect more than three years, not the state where it had been in effect less than one year (Table 1). This finding needs to be interpreted with some caution in that the perceived legal norm only positively worked to decrease the frequency of texting while driving for those who lived in the state where no banning law was in effect at all. The perceived legal norm seemed to be evoking psychological reactance to exhibit the reverse of the suggested behavior - not to text while driving - among those in Wisconsin and strongly in Florida, in particular (Fig. 1, left-hand side image).

This finding implies that the presence of legal enforcement did not warrant its automatic, positive translation to one's attentiveness to the external force to regulate the behavior of texting while driving at a perceptual level. Instead, young drivers would gradually learn about the enforcement of the banning law. It took a while, presumably at least more than one year, given the situations of two states included in this study, that this learning outcome would reflect on their behavior. Furthermore, the psychological response to the presence of legal enforcement was apparently negative, evoking resistance rather than cooperation (Fig. 1, left-hand side image). Publicity could have primed the participants in Florida about the banning law more than those in the other two states, as the banning law was relatively new in Florida at the time of data collection. As a result, exposure to 
a possibly great amount of publicity about the law implementation could have spurred the young drivers to confront the banning law by adhering to the prevalent practice of texting while driving (Fig. 1, left-hand side image). Concerning the psychological reactance, previous studies have found that suggesting a behavior that was apparently not concurrent with the behavior anticipated by people would likely yield negative results, and sometimes strong resistance when the suggestion exceeded their tolerance level to limit their free will to make a decision (Brehm \& Cole, 1966). Such a dark side of legally forcing the behavior of no texting while driving, however, can threaten to make legislative efforts impractical. Therefore, a forceful nature of regulation system for texting-while-driving behavior apparently not only backfired on the actual behavior in terms of its short-term effect, but also required a long-term exposure of the law itself for young drivers to change their behavior.

This finding is also aligned with the notion of internalization regarding consciousness about undesirable outcomes caused by reckless behaviors (Pawson et al., 2011). The perceived legal norm, even if seamlessly translating from the mere presence of law enforcement, would not be promising to effectively control texting-while-driving behavior because the focus on outcomes is not valuable or lasting, but trivial or transient. In fact, legal enforcement has shown some effect, although temporary, on halting the tendency of ill behaviors only when people showed compliance with the law along with internalization of the law. The internalization of legal enforcement among individuals is likely to emerge when there is public consent to not only the motives behind enforcing the law but also the benefits of implementation of the law (Pawson et al., 2011). The sanction of being legally confined is limited to a physical effect, which could not be very relatable to drivers until the drivers are eventually caught by police and encounter legal actions.

\subsection{The need for cultivating a moral norm to regulate texting while driving}

An encouraging finding from the present study is that young drivers' internal regulation system driven by moral beliefs exhibited negative relationships with attitudinal and behavioral outcomes related to the engagement in texting while driving. Consistent with expectations, the greater the perceived moral norm is, the lower frequency of texting while driving. The finding adds empirical support to the existing literature regarding the effectiveness of internally driven motivations to perform (or not to perform) a behavior (Deci et al., 1994). It must be noted that a particular psychological state elicited by moral beliefs is distinguished from self-oriented psychological states such as competence, autonomy, and relatedness (Deci \& Ryan, 1985). The moral norm is guided by solid life values, and is therefore hardly swayed by external stimuli (Gauld et al., 2014). The solid life values must resonate with one's realization of the benefits of not texting while driving, not only for the drivers themselves but also others who could be potential victims of the critical consequences of such behavior.

In this sense, cultivation of a moral norm to regulate the behavior of texting while driving is particularly encouraged in that the stable nature of this psychological variable can play a role to suppress possible reactance evoked by an external force. In particular, as people acknowledge the 
risks of texting while driving because of its life-threatening consequences to both drivers and others (e.g., Atchley et al., 2011, 2012), the emphasis of morality would be powerful because the moral norm has showed significant influences on behavior changes only when people could easily estimate the gravity of the consequences of their behavior (Godin et al., 2005). Unfortunately, the current prevalent culture of texting while driving gives young drivers the impression that people would understand their reckless behavior at a moment although they know people, including themselves, are not supposed to approve of it (e.g., Atchley et al., 2012). If this culture cannot be easily dismissed, it might be wiser to turn the focus of this behavior to its consequences and drivers' responsibility for not engaging in the behavior. An additional analysis of variance with the state as a predictor and perceived moral norm as an outcome variable provides the support to this argument such that the participants in Wisconsin showed a greater level of their perceived moral norm than those in South Carolina but not in Florida (Table 1). However, the role of perceived moral norm in inhibiting the texting-while-driving behavior is still subject to the influence of the negative role of perceived legal norm (Fig. 3). Therefore, it is imperative for policy makers to carefully implement a banning law with a strategy to hold the positive aspect of a driver's moral belief to not text while driving.

\subsection{Study limitations and future research}

One of limitations of the present study is a small sample size gathered from each state. However, even with the small number of cases, the present study found significant effects that demonstrate the relationships among three predictors and outcome variables. One concern surrounding the main effect of perceived legal norm could rise from this issue of small sample size due to possible Type II error (Tabachnick \& Fidell, 2013). The finding could gain more validity and clarity if the standardized coefficient were greater than the values reported when the sample size increases.

Another limitation is that the findings of present study could not claim causal relationships among the measured variables (Watt \& van den Berg, 1995). Some might possibly argue that the prominence of legal enforcement might be the reason why the participants in Florida particularly exhibited strong resistance by showing more frequency of texting while driving as well as intention to text while driving, since the start of the state's banning law less than 6 months prior to the time of data collection. Others also might suspect that no causal relationships between predictors and outcome variables were determined because the predictors were measured, not manipulated (Watt \& van den Berg, 1995). This is one reason why the present study focused on explaining the association between the predictors and outcome variables instead of "effects" of predictors on outcome variables when interpreting the statistical results. ${ }^{3}$ Future research is definitely encouraged to investigate direct causal relationships among the variables.

Some might also claim that the findings do not seem valid regarding the difference of the frequency of texting while driving between Wisconsin (lower) and the other two states (higher) because of participants' social desirability to manage their personal impression while participating in the survey

\footnotetext{
${ }^{3}$ The term was used in the result section for the purpose of analytical reports.
} 
(Marlowe \& Crowne, 1961). It is acknowledged that the present study did not specifically measure individual participants' social desirability. However, this claim could be canceled out because it is unlikely that social desirability could differ across states since this particular personality variable would not be influenced by the state of residency. Furthermore, it is likely that most of the participants could exhibit a high level of social desirability, if any, for this particular reckless behavior because the social norm of no texting while driving is so obvious to everyone when the behavior is questioned.

\subsection{Conclusion}

Nonetheless, based on the findings from the present study, policy makers are encouraged to harness their approach to regulate young drivers' texting while driving with the strategy that appeals to the drivers' inner sense of complying with their moral beliefs rather than simply forcing them to comply with the law. One might argue that a law banning such behavior will inevitably be enforced. Therefore, governments in various countries around the world tend to simply rely on law enforcement to regulate drivers' distracted behaviors such as texting while driving (e.g., BackerGrondahl \& Sagberg, 2011; Hallett, Lamber, \& Regan, 2011; Shi et al., 2016; Vollrath et al., 2016). In some cases, strict prohibition of texting while driving by means of the law (e.g., increasing the fine from CDN $\$ 60$ to $\$ 240$ in Ontario, Canada) has yielded a positive outcome of decreasing the percentage of drivers who engage in texting while driving (e.g., Tucker et al., 2015). However, the publicity efforts of law enforcement, including public campaigns, need to emphasize the moral obligation not to text while driving. It cannot be overlooked that texting while driving brings serious consequences both to drivers and to others who could be involved in accidents (Bingham et al., 2015). Therefore, as the present study found, the internalization of moral beliefs is critical to changing the distracted behavior of texting while driving, especially when the history of legal enforcement can interact with the establishment of strong moral beliefs to make them negatively correlated with the intention and actual behavior of texting while driving, as evidenced in the present study.

\section{References}

Ajzen, I. (1991). The theory of planned behavior. Organizational Behavior and Human Decision Processes, 50, 179-211.

Atchley, P., Atwood, S., \& Boulton, A. (2011). The choice to text and drive in younger drivers: Behavior may shape attitude. Accident Analysis and Prevention, 43, 134-142.

Atchley, P., Hadlock, C., \& Lane, S. (2012). Stuck in the 70s: The role of social norms in distracted driving. Accident Analysis and Prevention, 48, 279-284. BackerGrondahl, A., \& Sagberg, F. (2011). Driving and telephoning: Relative accident risk when using hand-held and hands-free mobile phones. Safety Science, 49, 324-330. https://doi.org/10.1016/j.ssci.2010.09.009.

Baier, M. (2013). Relations between social and legal norms. In M. Baier (Ed.), Social and legal norms: Toward a socio-legal understanding of normativity (pp. 53-70). 
Farnham, Surrey: Ashgate.

Bayer, J. B., \& Campbell, S. W. (2012). Texting while driving on automatic: Considering the frequency-independent side of habit. Computers in Human Behavior, 28, 2083-2090. https://doi.org/10.1016/j.chb.2012.06.012.

Beanland, V., Fitzharris, M., Young, K. L., \& Lenné, M. G. (2013). Driver inattention and driver distraction in serious casualty crashes: Data from the Australian National Crash in-depth study. Accident Analysis and Prevention, 54, 99-107.

Beck, K. H., \& Watters, S. (2016). Characteristics of college students who text while driving: Do their perceptions of a significant other influence their decisions? Transportation Research Part F, 37, 119-128. https://doi.org/10.1016/j.trf.2015.12.017.

Booth, B. M., Stewart, K. E., Curran, G. M., Cheney, A. M., \& Borders, T. F. (2014). Beliefs and attitudes regarding drug treatment: Application of the Theory of Planned Behavior in African-American cocaine users. Addictive Behaviors, 39, 14411446. https://doi.org/10.1016/j.addbeh.2014.05.012.

Benson, T., McLaughlin, M., \& Giles, M. (2015). The factors underlying the decision to text while driving. Transportation Research Part F, 35, 85-100. https:// doi.org/10.1016/j.trf.2015.10.013.

Brehm, J. W., \& Cole, A. H. (1966). Effect of a favor which reduces freedom. Journal of Personality and Social Psychology, 3(4), 420-426.

Deci, E. L., Eghrari, H., Patrick, B. C., \& Leone, D. (1994). Facilitating internalization: The self-determination theory perspective. Journal of Personality, 62, 119-142.

Deci, E. L., \& Ryan, R. M. (1985). Intrinsic motivation and self-determination in human behavior. New York: Plenum Press.

Elliott, M. A., Thomson, J. A., Robertson, K., Stephenson, C., \& Wicks, J. (2013). Evidence that changes in social cognitions predict changes in self-reported driver behavior: Causal analyses of two-wave panel data. Accident Analysis and Prevention, 50, 905916. https://doi.org/10.1016/j.aap.2012.07.017.

Federal Motor Carrier Safety Administration. (September 2009). Driver distraction in commercial vehicle operations. Publication FMCSA-RRR-09-045. Retrieved December 16, 2016 from <http://www.distraction.gov/downloads/pdfs/driverdistraction-commercial-vehicle-operations.pdf $>$.

Fishbein, M., \& Ajzen, I. (2010). Predicting and changing behavior: The reasoned action approach. New York: Psychology Press.

Foss, R. D., Goodwin, A. H., McCartt, A. T., \& Hellinga, L. A. (2009). Short-term effects of a teenage driver cell phone restriction. Accident Analysis and Prevention, 41, 419-424.

Gauld, S. C., Lewis, I., \& White, K. M. (2014). Concealing their communication: Exploring psychosocial predictors of young drivers' intentions and engagement in concealed texting. Accident Analysis and Prevention, 62, 285-293. https://doi.org/10.1016/j.aap.2013.10.016.

Godin, G., Conner, M., \& Sheeran, P. (2005). Bridging the intention-behaviour 'gap': The role of moral norm. British Journal of Social Psychology, 44, 497-512. Goodwin, A. 
H., O’Brien, N. P., \& Foss, R. D. (2012). Effect of North Carolina's restriction on teenage driver cell phone use two years after implementation. Accident Analysis and Prevention, 48, 363-367.

Governors Highway Safety Association (2016). Distracted driving laws Retrieved from http://www.ghsa.org/html/stateinfo/laws/cellphone_laws.html. Hallett, C., Lamber, A., \& Regan, M. A. (2011). Cell phone conversing while driving in New Zealand: Prevalence, risk perception and legislation. Accident Analysis and Prevention., 43, 862-869. https://doi.org/10.1016/j.aap.2010.11.006.

Hallett, C., Lamber, A., \& Regan, M. A. (2012). Text messaging amongst New Zealand drivers: Prevalence and risk perception. Transportation Research Part F, 15, 261271. https://doi.org/10.1016/j.trf.2011.12.002.

Jacobson, P. D., \& Gostin, L. O. (2010). Reducing distracted driving: Regulation and education to avert traffic injuries and fatalities. JAMA, 303(14), 1419-1420.

Lewis, T. F., \& Thombs, D. L. (2005). Perceived risks and normative beliefs as explanatory models for college student alcohol involvement: An assessment of a campus with conventional alcohol control policies and enforced practices. NASPA Journal, 42(2), 202-222.

Ling, R., Bertel, F., \& Sundsøy, P. R. (2012). The socio-demographic of texting: An analysis of traffic data. New Media and Society, 14, 281-297.

Lipperman-Kreda, S., Paschall, M., \& Grube, J. W. (2009). Perceived local enforcement, personal beliefs, and underage drinking: An assessment of moderating and main effects. Journal of Studies on Alcohol and Drugs, 70(1), 64-69.

Manning, M. (2009). The effects of subjective norms on behaviour in the theory of planned behaviour: A meta-analysis. The British Psychological Society, 48, 649705.

Manning, M. (2011). When we do what we see: The moderating role of social moderation on the relation between subjective norms and behavior in the theory of planned behavior. Basic and Applied Social Psychology, 33, 351-364.

Marcil, I., Bergreon, J., \& Audet, T. (2001). Motivational factors underlying the intention to drink and drive in youth male drivers. Journal of Safety Research, 32, 363-376.

Marlowe, D. A., \& Crowne, D. P. (1961). Social desirability and response to perceived situational demands. Journal of Consulting Psychology, 26, 79-83. Myklestad, I., \& Rise, J. (2008). Predicting intentions to perform protective sexual behaviours among Norwegian adolescents. Sex Education, 8, 107-124.

Neighbors, C., Lee, C. M., Lewis, M. A., Fossos, N., \& Larimer, M. E. (2007). Are social norms the best predictor of outcomes among heavy-drinking college students? Journal of Studies on Alcohol and Drugs, 68, 556-565.

Nemme, H. E., \& White, K. M. (2010). Texting while driving: Psychosocial influences on young people's texting intentions and behavior. Accident Analysis and Prevention, 42, 1257-1265. https://doi.org/10.1016/j.aap.2010.01.019.

NHTSA. (April 2016). Teen distracted driver data. Retrieved December 7, 2016 from $<$ https://crashstats.nhtsa.dot.gov/Api/Public/ViewPublication/812253>. Nurullah, 
A. S., Thomas, J., \& Vakilian, F. (2013). The prevalence of cell phone use while driving in a Canadian province. Transportation Research Part F, 19, 52-62. https://doi.org/10.1016/j.trf.2013.03.006.

O’Brien, N. P., Goodwin, A. H., \& Foss, R. D. (2010). Talking and texting among teenage drivers: A glass half empty or half full. Traffic Injury Prevention, 11, 549-554.

Paschall, M. J., Grube, J. W., Thomas, S., Cannon, C., \& Treffers, R. (2012). Relationships between local enforcement, alcohol availability, drinking norms, and adolescent alcohol use in 50 California cities. Journal of Studies on Alcohol and Drugs, 73, 657665.

Pawson, R., Wong, G., \& Owen, L. (2011). Known knowns, known unknowns, unknown unknowns: The predicament of evidence-based policy. American Journal of Evaluation, 32, 518-546. https://doi.org/10.1177/1098214011403831.

Prat, F., Gra, M. E., Planes, M., González-Iglesias, B., \& Sullman, M. J. M. (2015). Psychological predictors of texting while driving among university students. Transportation Research Part F, 34, 76-85. https://doi.org/10.1016/j.trf.2015.07.023.

Rimal, R. N., \& Lapinski, M. K. (2015). A re-explication of social norms, ten years later. Communication Theory, 25, 393-409. https://doi.org/ 10.1111/comt.12080.

Riquelme, H. E., Al-Sammak, F. S., \& Rios, R. E. (2010). Social influences among young drivers on talking on the mobile phone while driving. Traffic Injury Prevention, 11, $127-132$.

Shi, J., Xiao, Y., \& Atchley, P. (2016). Analysis of factors affecting drivers' choice to engage with a mobile phone while driving in Beijing. Transportation Research Part F, 37, 1-9. https://doi.org/10.1016/j.trf.2015.12.003.

Skierkowsk, D., \& Wood, R. M. (2012). To text or not to text? The importance of text messaging among college-aged youth. Computers in Human Behavior, 28, 744756. https://doi.org/10.1016/j.chb.2011.11.023.

Tabachnick, B. G., \& Fidell, L. S. (2013). Using multivariate statistics (6th ed.). Boston: Pearson.

Tian, Y., \& Robinson, J. D. (2016). Predictors of cell phone use in distracted driving: Extending the Theory of Planned Behavior. Health Communication. https:// doi.org/10.1080/10410236.2016.1196639. online first.

Tucker, s., Pek, S., Morrish, J., \& Ruf, M. (2015). Prevalence of texting while driving and other risky driving behaviors among young people in Ontario, Canada: Evidence from 2012 and 2014. Accident Analysis and Prevention, 84, 144-152. https://doi.org/10.1016/j.aap.2015.07.011.

Turchik, J. A., \& Gidycz, C. A. (2012). Prediction of sexual risk behaviors in college students using the theory of planned behavior: A prospective analysis. Journal of Social and Clinical Psychology, 31(1), 1-27.

Vollrath, M., Huemer, A. K., Teller, C., Likhacheva, A., \& Fricke, J. (2016). Do German drivers use their smartphones safely?-Not really! Accident Analysis and Prevention, 96, 29-38. https://doi.org/10.1016/j.aap.2016.06.003. 
Waddell, L. P., \& Wiener, K. K. K. (2014). What's driving illegal mobile phone use? Psychosocial influences on drivers' intentions to use hand-held mobile phones. Transportation Research Part F, 22, 1-11. https://doi.org/10.1016/j.trf.2013.10.008.

Watt, J. H., \& van den Berg, S. (1995). Research methods for communication science. Needham Heights, MA: Allyn \& Bacon.

Weller, J. A., Shackleford, C., Dieckmann, N., \& Slovic, P. (2012). Possession attachment predicts cell phone use while driving. Health Psychology, 32(4), 379-387. https://doi.org/10.1037/a0029265.

White, K. M., Hyde, M. K., Walsh, S. P., \& Watson, B. (2010). Mobile phone use while driving: An investigation of the beliefs influencing drivers' hands-free and handheld mobile phone use. Transportation Research Part F, 13, 9-20. https://doi.org/10.1016/j.trf.2009.09.004.

Wilson, F. A., \& Stimpson, J. P. (2010). Trends in fatalities from distracted driving from 1999-2008. American Journal of Public Health, 100(11), 2213-2219.

Zhou, R., Yu, M., \& Wang, X. (2016). Why do drivers use mobile phones while driving? The contribution of compensatory beliefs. PLoS ONE, 11(8), e0160288. https://doi.org/10.1371/journal.pone.0160288. 